\title{
New US agency to focus research aspect of development aid
}

\section{David Dickson reports from Washington on President Carter's proposal for a foundation for International Technological Cooperation}

ONE of the relatively few new initiatives in the budget recommendations submitted by President Carter to the US Congress last Monday was the proposal to establish, under the foreign aid appropriations, a Foundation for International Technological Cooperation (FITC).

The foundation is intended to act as the focus for the research and development component of the US development assistance effort. It is presently being conceived as one element in a proposed international development $\mathrm{co}$ operation administration, which would also include existing bodies such as the peace corps and the Agency for International Development (AID).

Funding for the FITC would be about $\$ 100$ million for the first year of full operation, beginning 1 October 1979 , although only a relatively small amount of this-about $\$ 25$ millionwould be new money, the majority of support resulting from the transfer of research projects currently carried out by AID. Eventually it is hoped that the foundations will have an annual budget of three to four hundred million dollars, the same order of magnitude as the National Science Foundation.

Plans for the foundation already figure prominently in the US national paper for the United Nations Conference on Science and Technology for Development (UNCSTD). However, criticisms of various aspects, such as the degree of autonomy which FITC will - or should-be able to exercise from existing aid programmes, and from overt US interests, indicate that the administration may face an uphill task in getting its plans accepted.

The proposed foundation was announced last March in a speech by President Carter in Caracas, Venezuela. It is largely the brain child of Dr Frank Press, director for the President's Office of science and technology policy, and reflects the same type of approach to $R \& D$ planning that he has injected into areas of domestic policy.

A planning office, reporting directly both to Dr Press and to Mr John G. Gilligan, administrator of AID, was established last summer. It is directed by $\mathrm{Dr}$ Ralph Schmuckler, previously dean of international studies and programmes at Michigan State University, and chairman of AID's research advisory board.

According to Dr Schmuckler, the foundation will have two main objectives, first, to help strengthen the scientific and technical problem-solving capacities of developing nations; and second to focus attention of US scientific resources on problems of concern to developing countries.

Although precise details are yet to be worked out, FITC is expected to operate by identifying various "problem-arcas" - in contrast to the countryby-country programming of bilateral aid programmes-and then to work out which are the crucial problems in these areas.

"The programming process will be a bit like a funnel. At the top we will have all types of state-of-the-art analyses, with participation by agencies already involved, by developing country representatives, and by scientists. We would then move from a broad sweep to an increasingly narrow focus on particularly important goals that could be realised over a period of five to ten years", Dr Schmuckler said.

To illustrate the type of research that might result from this process, he cites work being supported by AID on the possible production of a vaccine against malaria, "A good example of an analysed, research problem dealt with initially in a very low-cost way, but resulting in some scientific breakthroughs that offer the possibility of a solution to a major health problem".

Besides research itself, however, an equally important part of the foundation's activities will involve helping to build research infrastructures in developing countries-for example by

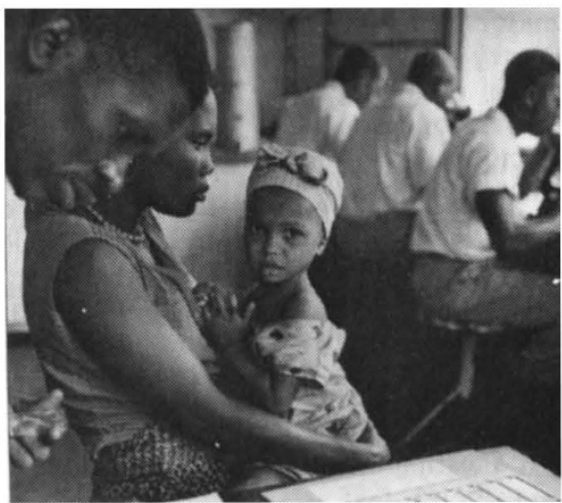

Above: protection against malaria. The disease disables $30-40 \%$ of the working population where the disease is rife. Research into a vaccine is "a good example" of the work FITC might undertake. assisting in the training of scientists and technologists through courses and seminars, and occasionally providing short-term financial support for local research initiatives.

"We aim to spend the majority of our money in the developing countries themselves-a rough estimate is $75 \%$,", says Dr Schmuckler. "The rest will go to US universities and research institutions, but only to support work which is directly tied to activities overseas",

And to ensure what he calls a "real live audience" for the foundation's efforts, roughly one-third of FITC's advisory council-which will be responsible for recommending areas for study to the foundation's director-will come from developing countries.

Legislation to set up the foundation is soon to be presented to Congress as part of an amendment to existing foreign aid legislation. However, there are already signs that various criticisms of the current plan could lead to a tough political battle.

One criticism, for example, is that the foundation will be so closely linked to existing agencies such as AID that it will not have sufficient autonomy to apply an objective analysis to third world research needs (although others point out that it may be necessary to emphasise US interests to get the FITC accepted by Congress).

"The basic idcas is a very good one -but I am not very happy about the way that things are working out, particularly since the foundation seems to be becoming a subsidiary of AID almost as soon as it is born", says Professor Michael J. Moravscik, professor of physics at the University of Oregon, and an active member of the recentlyformed Council on Science and Technology for Development.

Professor Moravscik and others are now putting their support behind an alternative proposal suggested by Senator Adlai Stevenson for a foundation for international scientific and technological cooperation, an agency similar in concept to the FITC, but having the power of autonomy enjoyed by the National Science Foundation.

A bill proposing such a FISTC is to be introduced into Congress by Senator Stevenson within the next few weeks. Attractive as the greater autonomy may be to some, however, its chances of success against the administration's FITC proposal, in a Congress increasingly concerned about public accountability for the use of federal funds, remains uncertain. 